\title{
Cesarean on request
}

\author{
Cesariana A Pedido
}

Authorship: Febrasgo, Sociedade Brasileira de Anestesiologia

Participants: Sergio F. de Toledo ${ }^{1}$, Ricardo Simões ${ }^{1,2}$, Luca S. Bernardo ${ }^{2}$, Wanderley M. Bernardo², Antônio J. Salomão ${ }^{1}$, Edmund C. Baracat ${ }^{1}$

\section{Conflict of interest: none}

${ }^{1}$ Federação Brasileira das Associações de Ginecologia e Obstetrícia (Febrasgo)

${ }^{2}$ Guidelines Project, Associação Médica Brasileira

The Guidelines Project, an initiative of the Brazilian Medical Association, aims to combine information from the medical field in order to standardize procedures to assist the reasoning and decision-making of doctors.

The information provided through this project must be assessed and criticized by the physician responsible for the conduct that will be adopted, depending on the conditions and the clinical status of each patient.

\section{INTRODUCTION}

The rates of $\mathrm{C}$-sections without medical or obstetric indication have increased substantially in the last decades, especially in developing countries. Many factors contribute to this increase, being the mother-requested cesarean delivery a contributing factor $(\mathbf{D}){ }^{1}$

There is a major debate about the implementation of C-sections performed at the mother's request without any established medical indication, and safety, cost, maternal autonomy, maternal and professional satisfaction, and ethics constitute important factors under discussion. These days, the practice of cesarean section on request constitutes a very important issue but, unfortunately, there is a lack of scientific studies to guide medical practice. Women over the decades became independent, modern and active in various professions, excelling compared to men. Their autonomy allows them to enjoy their own choices, including those related to their own body. In developed countries, they can choose whether or not to carry out an initial pregnancy, plastic surgery procedures, or even bariatric surgery.

Thus, detailed scientific studies in the context of evidence-based medicine are essential.

\section{Овjective}

To prepare a recommendation evaluating the risks and benefits involved in the practice of cesarean delivery on maternal request and $\mathrm{C}$-section without medical indication, compared to the planned vaginal delivery.

\section{Methods}

The evidence used for analysis of the risks and benefits involved in the practice of cesarean delivery on maternal request and $\mathrm{C}$-section without medical indication was obtained according to the following steps: preparation of the clinical question, structuring of the question, search for evidence, critical evaluation and selection of evidence.

\section{Clinical question}

Are nulliparous or multiparous women undergoing cesarean section, on request or without medical indication in term pregnancies, at increased risk of maternal and fetal complications compared to those undergoing planned vaginal delivery?

\section{Structured question}

The clinical question is structured according to the P.I.C.O. components: (P [patient]; I [intervention]; $\mathrm{C}$ [comparison]; O [outcome]).

- P: pregnancy to term;

- I: cesarean section on maternal request;

- C: vaginal deliver;

- O: maternal, perinatal and neonatal morbidity and mortality.

Bases of scientific data consulted

The scientific databases consulted were: PubMed-Medline and Cochrane. Manual search from revisions references (narrative or systematic) was also performed.

Strategies for search of evidence PubMed-Medline

Strategy: (cesarean* OR (cesarean sections OR delivery, abdominal OR abdominal deliveries OR deliveries, abdominal OR caesarean section OR caesarean sections OR abdominal delivery OR C-section (ob) OR C section (ob) OR C-sections (ob) OR postcesarean section)) AND (re- 
quest OR patient preference OR demand OR medical indication OR medical indications).

\section{Cochrane}

Strategy: cesarean section AND request.

Studies retrieved (4/15/2014) (Table 1)

TABLE 1 Number of studies retrieved with the search strategies used for each scientific database.

\begin{tabular}{ll} 
Database & Number of studies \\
\hline Primary & \\
\hline PubMed-Medline & 1,482 \\
\hline Cochrane & 54
\end{tabular}

\section{Inclusion criteria for studies retrieved}

Selection of studies, assessment of titles and abstracts obtained from the search strategy in the consulted databases was conducted by two researchers with skills in the preparation of systematic reviews, both independent and blinded, strictly observing the inclusion and exclusion criteria previously established. All potentially relevant studies were identified. Whenever the title and the summary were not enlightening, researchers sought the full article.

\section{Study design}

Narrative reviews, case reports, case series and studies presenting preliminary results were excluded from the assessment. Systematic reviews and meta-analyzes were used with the basic purpose of recovering references that perhaps had been lost at first, from the initial search strategy. Only comparative nonrandomized studies (strength of evidence $2 \mathrm{~B}$ and $2 \mathrm{C}$ ) were included.

\section{P.I.C.O. components}

- Patient: nulliparous or multiparous patients undergoing cesarean section on maternal request or without medical indication, at term, pre- or intra-labor, and women undergoing planned vaginal delivery at term.

- Intervention: cesarean section on maternal request or cesarean delivery without medical indication.

- Comparison: patients undergoing planned vaginal delivery.

- Outcome: the outcomes were divided into maternal outcomes, newborn outcomes and emergency cesarean. Maternal outcomes include: maternal death, bleeding complications, infectious complications, wound complications, complications in breastfeeding. Bleed- ing complications were defined in the study as bleeding $\geq 1,000 \mathrm{~mL}$, need for blood transfusion after delivery, need for curettage due to placental persistence, anemia, prolonged vaginal bleeding and hysterectomy caused by bleeding. Maternal infectious complications are defined as urinary tract infections, endometritis and sepsis. Wound complications were classified as wound infection, dehiscence or pain. Complications in breastfeeding are defined as mixed feeding or feeding with formula only. Newborn outcomes include: Apgar score lower or equal to 7, asphyxia, respiratory complications, infection, and need for admission to neonatal ICU. Asphyxia was defined as $\mathrm{pH}$ of venous blood or blood cord lower than 7.0. Respiratory complications were defined according to studies of respiratory distress syndrome of the newborn, use of CPAP, need for ventilation, and dyspnea or tachypnea.

\section{Language}

The authors included studies available in Portuguese, English, French or Spanish.

\section{According to publication}

Only studies with full text available were considered for critical assessment.

\section{Studies selected in the first assessment}

Using the search strategy described, 1,482 studies were retrieved. Out of these, which were reviewed based on title, only 295 articles included the subject cesarean delivery on maternal request or C-section without medical indication, and thus 1,187 studies were excluded. Of the 295 studies, only 73 were selected for full text review, being considered for final evaluation 9 comparative studies (observational cohorts) that met the criteria for inclusion and exclusion (Flowchart 1).

Evidence selected in critical evaluation and exhibition of results The studies considered for full text reading were critically assessed according to inclusion and exclusion criteria, study design, P.I.C.O., language and availability of the full text.

Results of the clinical situations are displayed in Tables 4,5 and 6 .

References related to the studies included are shown in Table 3, and are also presented in the section References.

After applying the inclusion and exclusion criteria, the evidence selected in the search and defined as randomized controlled trials (RCT) were subjected to an appropriate checklist for critical assessment (Table 2). Crit- 


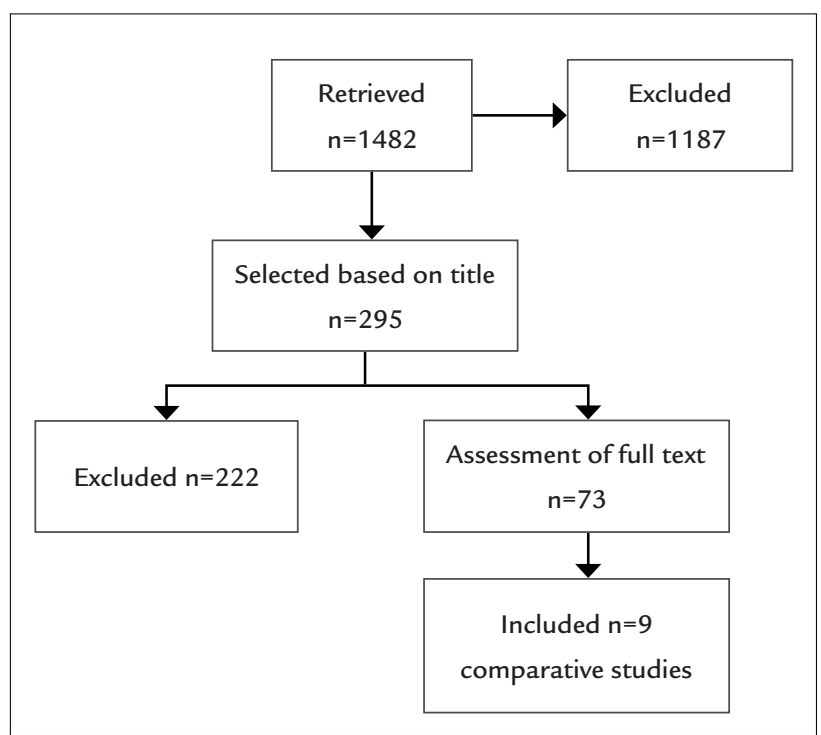

FLOWCHART 1 Study selection.

ical assessment of RCTs allows to classify them according to the Jadad score, so that Jadad $<3$ trials are considered inconsistent (B), and those with scores $\geq 3$, consistent (A). For critical analysis of non-randomized studies, among them prospective observational studies, the authors used the Newcastle-Ottawa scale. ${ }^{8}$

For results with available evidence, wherever possible, the following specific items are defined: population, intervention, outcomes, the presence or absence of benefit and/or damage and controversies.

Cost issues will not be included in the results.

The results will be presented preferably in absolute data, absolute risk, number needed to treat (NNT), or number needed to harm (NNH), and occasionally in mean and standard deviation.

\section{Statistical analysis}

The measures of effectiveness or damage expressed in absolute numbers were analyzed using the difference in absolute risk, adopting a confidence interval of $95 \%$. For statistically significant results, the number needed to treat to benefit (NNT) and the number needed to treat to harm (NNH) were calculated. The meta-analysis was performed using RevMan 5 (Review Manager, Cochrane Collaboration, 2008) software.

\section{Heterogeneity}

Inconsistencies among the clinical trials were evaluated for heterogeneity using chi-square test $\left(\mathrm{Chi}^{2}\right)$ and quantified through $\mathrm{I}^{2}$ test. Values above $50 \%$ were considered significant.
TABLE 2 Critical assessment script for randomized controlled trials (checklist).

\begin{tabular}{ll}
$\begin{array}{l}\text { Study data } \\
\text { Reference, study design, Jadad, } \\
\text { strength of evidence }\end{array}$ & $\begin{array}{l}\text { Sample size calculation } \\
\text { Estimated differences, power, } \\
\text { significance level, total number } \\
\text { of patients }\end{array}$ \\
\hline $\begin{array}{l}\text { Patient selection } \\
\text { Inclusion and exclusion criteria }\end{array}$ & $\begin{array}{l}\text { Patients } \\
\text { Recruited, randomized, } \\
\text { prognostic differences }\end{array}$ \\
\hline Randomization & Patient follow-up \\
allocation & Time, losses, migration \\
\hline Treatment protocol & Analysis \\
Intervention, control and & Intention to treat, analyzes of \\
blinding & intervention and control \\
\hline $\begin{array}{l}\text { Outcomes considered } \\
\text { Primary, secondary, measuring } \\
\text { instrument of the outcome of } \\
\text { interest }\end{array}$ & $\begin{array}{l}\text { Result } \\
\text { Benefit or harm in absolute }\end{array}$ \\
\hline
\end{tabular}

\section{Results}

Evidence selected

\section{TABLE 3 Selection process.}

\begin{tabular}{ll} 
Type of publication & Included \\
\hline Nonrandomized comparative & $9^{2-10}$ \\
studies & \\
\hline
\end{tabular}

The main reasons for the exclusion of works were: the unavailability of the full text; nonrandomized comparative studies with different study design; studies that included preterm fetuses (gestational age $<37$ weeks), or those using only the estimated weight of the fetus as a criterion for inclusion. The graphics of the meta-analysis relating to the works included in the assessment are shown in the Appendix.

The average gestational age is significantly lower in the group of cesarean delivery with no indication as compared to the planned vaginal delivery group in four of the five studies evaluating this outcome (Table 4) (B). ${ }^{3-6,9}$ The mean birth weight is assessed in five studies, and in one work, only the mean weight is significantly higher in the cesarean group without indication (Table 5) (B)..$^{3-6,8}$

\section{Effect of cesarean section on maternal request or without} indication on maternal mortality

Three studies evaluate maternal mortality $(\mathbf{B}) ;^{2-4}$ however, only one study has events for this outcome $(\mathbf{B}) .{ }^{8}$ The 
study shows an absolute risk reduction of maternal mortality of $3.0 \%$ in favor of cesarean section on maternal request or without indication; however, this decrease is not significant (95CI: -0.14 to 0.07 ; Table 4 ).

\section{Effect of cesarean section on maternal request or without indication on bleeding complications}

Seven studies assessed maternal bleeding complications after delivery $(\mathbf{B}) .^{2,3-8}$ Based on simple averages, the rate of bleeding complications in the group of cesarean section on maternal request without medical indication is 5.8 versus $1.3 \%$ in the group of vaginal delivery, demonstrating an increase in the absolute risk of $4.5 \%$. Thus, 22 patients need to undergo cesarean section for a bleeding complication to occur $(\mathrm{NNH}=22)$. In the meta-analysis, the results of studies have shown that cesarean section on maternal request or without medical indication increases by $1.0 \%$ (95CI: 0.01 to $0.02 ; \mathrm{p}<0.00001 ; \mathrm{I}^{2}=96 \%$; Figure 1.1) the absolute risk of bleeding complications compared to planned vaginal delivery.

Effect of cesarean section on maternal request or without indication on infectious complications

The rate of infectious complications demonstrated by simple average in the group of cesarean delivery on maternal request or without indication is 2.2 versus $0.5 \%$ in the group of planned vaginal delivery. The development of infectious complications after cesarean delivery was evaluated in five studies $(\mathbf{B}),{ }^{3-8}$ which, in the meta-analysis demonstrated an increase of $1.0 \%$ (95CI: 0.01 to 0.01 ; $\mathrm{p}<0.00001 ; \mathrm{I}^{2}=98 \%$; Figure 1.2) in absolute risk of infectious complications in the cesarean delivery group.

Effect of cesarean section on maternal request or without indication on wound complications

Four studies $(\mathbf{B})^{3-7}$ evaluate the incidence of wound complications after cesarean or vaginal delivery. The incidence of wound complications obtained by simple average in the group of cesarean delivery on maternal request or without indication is $2.2 \%$, while in the planned vaginal delivery group, it is $0.6 \%$. However, there is no significant increase or decrease (95CI: -0.00 to $0.01 ; \mathrm{p}=0.50 ; \mathrm{I}^{2}=0 \%$; Figure 1.3 ) in the risk of wound complications between the groups according to the assessment made by the meta-analysis.

Effect of cesarean section on maternal request or without indication on breastfeeding

The studies $(\mathbf{B})^{5,9}$ assessed the association between cesarean section on maternal request or without indication and complications in breastfeeding. The simple average of all the studies revealed that the rate of breastfeeding complications in the group of cesarean delivery on maternal request is 8.4 versus $7.4 \%$ in the group of planned vaginal delivery. Therefore, 100 patients are required to undergo cesarean delivery without medical indication so that one can present breastfeeding complications $(\mathrm{NNH}=100)$. The results demonstrate that cesarean delivery on maternal request or without indication is associated with an increase of $2.0 \%$ (95CI: 0.02 to $0.03 ; p<0.00001$; Figure 1.4 ) in the risk of complications related to exclusive breastfeeding.

Incidence of emergency cesarean section without indication and planned vaginal delivery

Five studies $(\mathbf{B})^{3-6,8}$ evaluate the progression to emergency cesarean delivery from cesarean delivery on maternal request or without indication and vaginal delivery, so that the emergency cesarean delivery rate in the cesarean delivery group maternal request is $1.6 \%$, while in the group of planned vaginal delivery, the rate is $12.8 \%$ based on the evaluation of the simple average of all studies.

Vaginal delivery has a significant increase of $9.0 \%$ (95CI: -0.09 to $-0.9 ; \mathrm{p}<0.00001 ; \mathrm{I}^{2}=100 \%$; Figure 2 ) in the absolute risk of progression to emergency cesarean delivery compared to cesarean delivery without indication as demonstrated by the meta-analysis.

Effect of cesarean section on maternal request or without indication on the Apgar score

Three studies $(\mathbf{B})^{3-5}$ evaluated the influence of cesarean delivery on maternal request on Apgar score. The group of cesarean delivery on maternal request has a lower incidence of Apgar score reduction compared to the group of planned vaginal delivery ( 0.47 versus $0.82 \%$ ), according to the evaluation of average for all the groups. Therefore, 286 patients are required to undergo cesarean delivery without medi$\mathrm{cal}$ indication in order to one have one newborn with no reduction in Apgar score $(\mathrm{NNT}=286)$ (Table 6). The metaanalysis shows significant reduction in the absolute risk of $1.0 \%$ (95CI: -0.01 to $-0.01 ; \mathrm{p}<0.00001 ; \mathrm{I}^{2}=98 \%$; Figure 3.1 ).

Effect of cesarean section on maternal request or without indication on the occurrence of neonatal asphyxia

In the group of cesarean delivery on maternal request, the rate of neonatal asphyxia $(\mathbf{B})^{3-5}$ is $0.06 \%$, while the rate in the group of planned vaginal delivery is $0.25 \%$, based on the average of all studies. There is no significant reduction in absolute risk regarding the rate of asphyxia between the two groups (95CI: -0.01 to -0.00 ; $\mathrm{p}=0.0002$; $\mathrm{I}^{2}=88 \%$; Figure 3.2) (Table 6), although there is a difference shown in the meta-analysis chart. 
TABLE 4 Maternal complications.

\section{C-section without medical indication $\mathbf{n}$}

Average gestational age (SD)

\begin{tabular}{|c|c|c|c|c|c|c|c|c|}
\hline \multicolumn{9}{|c|}{ Average gestational age (SD) } \\
\hline Karlström 2013 & $38.40( \pm 0.73)$ & \multicolumn{2}{|l|}{5877} & $39.81( \pm 1.17)$ & \multicolumn{3}{|l|}{12936} & $<0,0000001$ \\
\hline Crowther 2012 & $38.8( \pm 0.7)$ & \multicolumn{2}{|l|}{1098} & $40( \pm 1.1)$ & \multicolumn{3}{|l|}{1225} & $<0,0000001$ \\
\hline Liu 2012 & $40.2( \pm 1.0)$ & \multicolumn{2}{|l|}{22462} & $40.1( \pm 1.0)$ & \multicolumn{3}{|l|}{409242} & $<0.0000001$ \\
\hline Larsson 2011 & 38 & \multicolumn{2}{|l|}{247} & 40 & \multicolumn{3}{|l|}{294} & - \\
\hline \multirow[t]{3}{*}{ Dahlgren 2009} & $38.56( \pm 0.91)$ & \multicolumn{2}{|l|}{1046} & $39.29( \pm 1.11)$ & \multicolumn{3}{|l|}{38021} & $<0,0000001$ \\
\hline & \multirow[t]{2}{*}{ C-section without indication } & \multirow[t]{2}{*}{$\mathbf{n}$} & \multirow[t]{2}{*}{$\mathrm{RA}_{\mathrm{PC}}$} & \multirow[t]{2}{*}{ Vaginal delivery } & \multirow[t]{2}{*}{ n } & \multirow[t]{2}{*}{$\mathrm{RA}_{\mathrm{pV}}$} & RRA(-) & \multirow[t]{2}{*}{$\mathrm{Cl}$} \\
\hline & & & & & & & $\operatorname{ARA}(+)$ & \\
\hline \multicolumn{9}{|c|}{ Maternal death } \\
\hline Crowther 2012 & 0 & 1098 & 0.0 & 0 & 1225 & 0.0 & 0.0 & - \\
\hline Souza 2010 & 2 & 2685 & $0.07 \%$ & 230 & 212847 & $0.11 \%$ & $-0.03 \%$ & $-0.14,0.07$ \\
\hline Dahlgren 2009 & 0 & 1046 & 0.0 & 0 & 38021 & 0.0 & 0.0 & - \\
\hline \multicolumn{9}{|c|}{ Bleeding complications (\%) } \\
\hline Karlström 2013 & $579(9.9)$ & 5877 & $9.85 \%$ & $935(6.8)$ & 13774 & $6.79 \%$ & $3.06 \%$ & $2.19,3.93$ \\
\hline Crowther 2012 & $9(0.8)$ & 1098 & $0.82 \%$ & $29(2.4)$ & 1225 & $2.37 \%$ & $-1.55 \%$ & $-2.55,-0.54$ \\
\hline Larsson 2011 & $25(10)$ & 247 & $10.12 \%$ & $41(14)$ & 294 & $13.95 \%$ & $-3.82 \%$ & $-9.28,1.64$ \\
\hline Souza 2010 & $27(1.0)$ & 2685 & $1.01 \%$ & $3613(1.4)$ & 256518 & $1.41 \%$ & $-0.40 \%$ & $-0.78,-0.02$ \\
\hline Wang 2010 & $12(4.0)$ & 301 & $3.99 \%$ & $2(0.6)$ & 301 & $0.66 \%$ & $3.32 \%$ & $0.93,5.71$ \\
\hline Dahlgren 2009 & $3(0.29)$ & 1046 & $0.29 \%$ & $123(0.32)$ & 38021 & $0.32 \%$ & $-0.04 \%$ & $-0.37,0.29$ \\
\hline Schindl 2003 & $0(0.0)$ & 147 & 0.0 & $17(1.8)$ & 903 & $1.88 \%$ & $-1.88 \%$ & $-2.77,-0.99$ \\
\hline \multicolumn{9}{|c|}{ Infectious complications (\%) } \\
\hline Karlström 2013 & $148(2.5)$ & 5877 & $2.52 \%$ & $155(1.1)$ & 13774 & $1.12 \%$ & $1.39 \%$ & $0.95,1.83$ \\
\hline Larsson 2011 & 8 & 247 & $3.24 \%$ & 8 & 294 & $2.72 \%$ & $0.52 \%$ & $-2.37,3.40$ \\
\hline Wang 2010 & $7(2.3)$ & 301 & $2.33 \%$ & $3(1.0)$ & 301 & $0.99 \%$ & $1.33 \%$ & $-0.71,3.37$ \\
\hline Dahlgren 2009 & $1(0.1)$ & 1046 & $0.10 \%$ & $104(0.27)$ & 38021 & $0.27 \%$ & $-0.18 \%$ & $-0.37,0.02$ \\
\hline Schindl 2003 & $0(0.0)$ & 147 & 0.0 & $1(0.1)$ & 903 & $0.11 \%$ & $-0.11 \%$ & $-0.33,0.11$ \\
\hline \multicolumn{9}{|c|}{ Wound complications (\%) } \\
\hline Crowther 2012 & $18(1.6)$ & 1098 & $1.64 \%$ & $13(1.1)$ & 1225 & $1.06 \%$ & $0.58 \%$ & $-0.37,1.53$ \\
\hline Larsson 2011 & $0(0.0)$ & 247 & 0.0 & $1(0.3)$ & 294 & $0.34 \%$ & $-0.34 \%$ & $-1.01,0.32$ \\
\hline Wang 2010 & 31 & 301 & $10.3 \%$ & 32 & 301 & $10.6 \%$ & $-0.33 \%$ & $-5.22,4.56$ \\
\hline Dahlgren 2009 & $10(0.96)$ & 1046 & $0.96 \%$ & $189(0.5)$ & 38021 & $0.50 \%$ & $0.46 \%$ & $-0.13,1.05$ \\
\hline \multicolumn{9}{|c|}{ Breastfeeding complications (\%) } \\
\hline Karlström 2013 & $73(1.2)$ & 5877 & $1.24 \%$ & $32(0.2)$ & 13774 & $0.23 \%$ & $1.01 \%$ & $0.71,1.30$ \\
\hline Liu 2012 & $2317(10.3)$ & 22462 & $10.32 \%$ & $31211(7.6)$ & 409242 & $7.63 \%$ & $1.35 \%$ & $2.28,3.09$ \\
\hline
\end{tabular}

P values $<0.05$ and confidence intervals that exclude null values are in bold.

TABLE 5 Emergency C-section.

Vaginal delivery $\mathbf{n}$

p

\section{Maternal death}

\section{C-section without indication $\mathbf{n}$}

RA $_{\mathrm{PC}}$ Vaginal delivery $\mathbf{n}$

\section{$\mathrm{RA}_{\mathrm{PV}} \quad \mathrm{RRA}(-) \quad \mathrm{Cl}$}

$\mathrm{ARA}(+)$

\begin{tabular}{lllllllll}
\hline Karlström 2013 & 0 & 5877 & 0.0 & 838 & 13774 & $6.08 \%$ & $-6.08 \%$ & $\mathbf{- 6 . 4 8 , - 5 . 6 8}$ \\
\hline Crowther 2012 & $109(9.9)$ & 1098 & $9.93 \%$ & $367(30)$ & 1225 & $29.96 \%$ & $-20.0 \%$ & $\mathbf{- 2 3 . 1 5 , - 1 6 . 9 2}$ \\
\hline Larsson 2011 & $25(10)$ & 247 & $10.12 \%$ & $45(15.4)$ & 294 & $15.31 \%$ & $-5.18 \%$ & $-10.76,0.39$ \\
\hline Dahlgren 2009 & $0(0.0)$ & 1046 & 0.0 & $5580(14.7)$ & 38021 & $14.68 \%$ & $-14.7 \%$ & $\mathbf{- 1 5 . 0 3 , - 1 4 . 3 2}$ \\
\hline Schindl 2003 & $0(0.0)$ & 147 & 0.0 & $93(10.3)$ & 903 & $10.3 \%$ & $-10.3 \%$ & $-12.28,-8.32$ \\
\hline
\end{tabular}

$P$ values $<0.05$ and confidence intervals that exclude null values are in bold. 


\section{TABLE 6 Newborn complications.}

\begin{tabular}{|c|c|c|c|c|c|c|c|c|}
\hline & C-section without indication & \multicolumn{2}{|l|}{$\mathbf{n}$} & Vaginal delivery & \multicolumn{3}{|l|}{$\mathbf{n}$} & $\mathbf{p}$ \\
\hline \multicolumn{9}{|c|}{ Average birth weight (SD) } \\
\hline Karlström 2013 & $3558( \pm 448)$ & \multicolumn{2}{|l|}{5877} & $3665( \pm 467)$ & \multicolumn{3}{|l|}{12936} & $<0,0000001$ \\
\hline Crowther 2012 & $3462( \pm 451)$ & \multicolumn{2}{|l|}{1098} & $3571( \pm 495)$ & \multicolumn{3}{|l|}{1225} & $<0,0000001$ \\
\hline Liu 2012 & $3438( \pm 393)$ & \multicolumn{2}{|l|}{22462} & $3332( \pm 375)$ & \multicolumn{3}{|l|}{409242} & $<0.0000001$ \\
\hline Larsson 2011 & 3339 & \multicolumn{2}{|l|}{247} & 3617 & \multicolumn{3}{|l|}{294} & $<0,001$ \\
\hline \multirow[t]{2}{*}{ Dahlgren 2009} & $3383.8( \pm 415.96)$ & \multicolumn{2}{|l|}{1046} & $3531.4( \pm 441.85)$ & \multicolumn{3}{|l|}{38021} & $<0,0000001$ \\
\hline & $\begin{array}{l}\text { C-section without medical } \\
\text { indication }\end{array}$ & $\mathbf{n}$ & $\mathbf{R A}_{\mathrm{PC}}$ & Vaginal delivery & $\mathbf{n}$ & $\mathbf{R A}_{\mathrm{PV}}$ & $\begin{array}{l}\text { RRA (-) } \\
\operatorname{ARA}(+)\end{array}$ & $\mathrm{Cl}$ \\
\hline \multicolumn{9}{|c|}{ Apgar score $\leq 7(\%)$} \\
\hline Karlström 2013 & $38(0.6)$ & 5877 & $0.65 \%$ & $252(1.8)$ & 13774 & $1.83 \%$ & $-1.18 \%$ & $-1.48,-0.88$ \\
\hline Crowther 2012 & $0(0.0)$ & 1098 & 0.0 & $1(0.1)$ & 1225 & $0.08 \%$ & $-0.08 \%$ & $-0.24,0.08$ \\
\hline Larsson 2011 & Average & - & & Average & - & & & \\
\hline Dahlgren 2009 & $0(0.0)$ & 1046 & 0.0 & $182(0.48)$ & 38021 & $0.48 \%$ & $-0.48 \%$ & $-0.55,-0.41$ \\
\hline \multicolumn{9}{|c|}{ Respiratory complications (\%) } \\
\hline Karlström 2013 & 159 & 5877 & $2.7 \%$ & 153 & 13774 & $1.11 \%$ & $1.59 \%$ & $1.14,2.04$ \\
\hline Crowther 2012 & 2 & 1098 & $0.18 \%$ & $1(0.1)$ & 1225 & $0.08 \%$ & $0.10 \%$ & $-0.20,0.40$ \\
\hline Dahlgren 2009 & 91 & 1046 & $8.7 \%$ & $2900(7.63)$ & 38021 & $7.63 \%$ & $1.07 \%$ & $-0.65,2.80$ \\
\hline Schindl 2003 & 1 & 147 & $0.68 \%$ & $0(0.0)$ & 903 & 0.0 & $0.68 \%$ & $-0.65,2.01$ \\
\hline \multicolumn{9}{|l|}{ Asphyxia (\%) } \\
\hline Karlström 2013 & $3(0.1)$ & 5877 & $0.05 \%$ & $78(0.5)$ & 13774 & $0.56 \%$ & $-0.51 \%$ & $-0.65,-0.38$ \\
\hline Crowther 2012 & $1(0.1)$ & 1098 & $0.09 \%$ & $6(0.5)$ & 1225 & $0.49 \%$ & $-0.40 \%$ & $-0.83,0.03$ \\
\hline Dahlgren 2009 & $1(0.1)$ & 1046 & $0.10 \%$ & $51(0.13)$ & 38021 & $0.13 \%$ & $-0.04 \%$ & $-0.23,0.15$ \\
\hline \multicolumn{9}{|l|}{ Infection (\%) } \\
\hline Karlström 2013 & $29(0.5)$ & 5877 & $0.11 \%$ & $111(0.8)$ & 13774 & $0.0 \%$ & $0.11 \%$ & $-0.11,0.33$ \\
\hline Crowther 2012 & $1(0.1)$ & 1098 & $0.09 \%$ & $4(0.3)$ & 1225 & $0.33 \%$ & $-0.23 \%$ & $-0.60,0.13$ \\
\hline Dahlgren 2009 & $1(0.1)$ & 1046 & $0.09 \%$ & $29(0.08)$ & 38021 & $0.08 \%$ & $0.02 \%$ & $-0.17,0.21$ \\
\hline \multicolumn{9}{|c|}{ Admission to neonatal ICU (\%) } \\
\hline Crowther 2012 & $4(0.4)$ & 1098 & $0.36 \%$ & $7(0.6)$ & 1225 & $0.57 \%$ & $-0.21 \%$ & $-0.76,0.34$ \\
\hline Larsson 2011 & $13(5.3)$ & 247 & $5.26 \%$ & $15(5.1)$ & 294 & $5.10 \%$ & $0.16 \%$ & $-3.59,3.91$ \\
\hline Souza 2010 & $33(1.2)$ & 2685 & $1.23 \%$ & $4532(1.8)$ & 256869 & $1.76 \%$ & $-0.53 \%$ & $-0.95,-0.11$ \\
\hline Wiklund 2007 & 5 & 99 & $5.05 \%$ & 12 & 237 & $5.06 \%$ & $-0.01 \%$ & $-5.15,5.12$ \\
\hline Schindl 2003 & $0(0.0)$ & 147 & 0.0 & $1(0.1)$ & 903 & $0.11 \%$ & $-0.11 \%$ & $-0.33,0.11$ \\
\hline
\end{tabular}

P values $<0.05$ and confidence intervals that exclude null values are in bold.

Effect of cesarean section on maternal request or without indication on respiratory complications

Four studies $(\mathbf{B})^{3-5,8}$ assessed the respiratory complications of the newborn related to cesarean delivery on maternal request or without indication. The average obtained from all studies demonstrate that respiratory complications in the cesarean group total 3.1 versus $5.7 \%$ in the group of planned vaginal delivery (Table 6). However, the meta-analysis shows that the cesarean delivery on maternal request is associated with a significant increase of $1.0 \%$ (95CI: 0.01 to $0.02 ; \mathrm{p}<0.00001 ; \mathrm{I}^{2}=96 \%$; Figure 3.3 ) in the absolute risk of the development of respiratory complications.

Effect of cesarean section on maternal request or without indication on the rate of newborn infection

The average of infectious complications $(\mathbf{B})^{3-5}$ in the group of cesarean delivery on maternal request is $0.4 \%$, while in the group of planned vaginal delivery the rate of infection is $0.3 \%$ (Table 6). Although there are differences in favor of cesarean delivery, the meta-analysis shows no significant 
reduction in the absolute risk of infection between the two groups (95CI: -0.00 to $-0.00 ; \mathrm{p}=0.02 ; \mathrm{I}^{2}=74 \%$; Figure 3.4 ).

Effect of cesarean section on maternal request or without indication on the rate of admission to neonatal ICU

The average hospital stay in neonatal ICU obtained from studies $(\mathbf{B})^{2,4,6,8,10}$ evaluating this outcome is $1.2 \%$ in the cesarean group, versus $1.8 \%$ in the group of planned vaginal delivery (Table 6). Despite the fact that the group of cesarean delivery on maternal request has a lower rate of neonatal ICU hospitalization compared to the group of planned vaginal delivery, based on the simple average of all studies, the meta-analysis shows that the reduction is not significant (95CI: -0.01 to $-0.00 ; \mathrm{p}=0.84 ; \mathrm{I}^{2}=0 \%$, Figure 3.5 ).

\section{Final RECOMmEndations}

The authors conclude that cesarean delivery on maternal request or without indication increases the risk of bleeding, infectious, breastfeeding and respiratory complications for the newborn. There was a reduction in the risk of emergency cesarean section and Apgar score $\leq 7 \mathrm{com}$ pared to planned vaginal delivery. Cesarean delivery on maternal request does not present significant increases or reductions in maternal mortality, post surgical wound complications, neonatal asphyxia, neonatal infection, and admission to neonatal ICU.

Based on this information and in the absence of maternal and/or fetal indications for resolution by cesarean delivery, a vaginal birth should be safe and suitable for recommendation to a pregnant woman. If, after the explanation of the risks and benefits of each obstetric resolution, showing every detail of the risks in each mode of delivery, the patient still rejects vaginal delivery, cesarean section should not be performed before 39 weeks of gestation. The cesarean delivery should be discouraged for patients who want more offspring, because of the risk of placenta accre$t a$, low insertion of placenta and hysterectomies in subsequent births; C-section should not be recommended as a painless option of delivery over vaginal delivery, either.

In this context, based on maternal request for cesarean section, the authors propose that the physician should try to know more deeply the personal values and preferences of the pregnant patient, addressing them in a process of shared decision-making $(\mathbf{A})^{11}(\mathbf{D}) .^{12,13}$ Thus, the declared and underlying motivations of the patient can be investigated, including the intense fear of childbirth, also known as tokophobia, and other factors associated with cesarean section on maternal request: previous complicated pregnancy; adverse experience in labor or delivery; anxious or avoidant personality traits; or history of sexual abuse $(\mathbf{D})^{14,15}(\mathbf{B}){ }^{16,17}$
Studies indicate that women undergoing cesarean at their own request have a higher frequency of psychopathological manifestations and psychiatric diseases. Specifically, a recent meta-analysis identified prevalence in the community of three percent for postpartum post-traumatic stress disorder (A). ${ }^{18}$ Cesarean section may be regarded by some patients as a resource to alleviate the suffering derived from anxious or depressive symptoms. Therefore, it is recommended that the doctor is also aware of the need for evaluation and treatment by a psychiatrist and/or psychologist with expertise in perinatal mental health.

\section{References}

1. NIH State-of-the-Science Conference Statement on cesarean delivery on maternal request. NIH Consens Sci Statements. 2006; 23(1):1-29.

2. Souza JP, Gülmezoglu A, Lumbiganon P, Laopaiboon M, Carroli G, Fawole B, Ruyan P; WHO Global Survey on Maternal and Perinatal Health Research Group. Caesarean section without medical indications is associated with an increased risk of adverse short-term maternal outcomes: the 2004-2008 WHO Global Survey on Maternal and Perinatal Health. BMC Med. 2010; 8:71.

3. Dahlgren LS, von Dadelszen P, Christilaw J, Janssen PA, Lisonkova S, Marquette GP, Liston RM. Caesarean section on maternal request: risks and benefits in healthy nulliparous women and their infants. J Obstet Gynaecol Can. 2009; 31(9):808-17.

4. Crowther CA, Dodd JM, Hiller JE, Haslam RR, Robinson JS; Birth After Caesarean Study Group. Planned vaginal birth or elective repeat caesarean: patient preference restricted cohort with nested randomised trial. PLoS Med. 2012; 9(3):e1001192.

5. Karlström A, Lindgren H, Hildingsson I. Maternal and infant outcome after caesarean section without recorded medical indication: findings from a Swedish case-control study. BJOG 2013; 120:479-86

6. Larsson C, Saltvedt S, Wiklund I, Andolf E. Planned vaginal delivery versus planned caesarean section: short-term medical outcome analyzed according to intended mode of delivery. J ObstetGynaecol Can. 2011; 33(8):796-802.

7. Wang BS, Zhou LF, Coulter D, Liang H, Zhong Y, Guo YN, et al. Effects of caesarean section on maternal health in low risk nulliparous women: a prospective matched cohort study in Shanghai, China. BMC Pregnancy Childbirth. 2010; 10:78.

8. Schindl M, Birner P, Reingrabner M, Joura E, Husslein P, Langer M. Elective cesarean section vs. spontaneous delivery: a comparative study of birth experience. Acta Obstet Gynecol Scand. 2003; 82(9):834-40.

9. Liu X, Zhang J, Liu Y, Li Y, Li Z. The association between cesarean delivery on maternal request and method of newborn feeding in China. PLoS One. 2012; 7(5):e37336.

10. Wiklund I, Edman G, Ryding EL, Andolf E. Expectation and experiences of childbirth in primiparae with caesarean section. BJOG. 2008; 115(3):324-31.

11. Lavender T, Hofmeyr GJ, Neilson JP, Kingdon C, Gyte GML. Caesarean section for non-medical reasons at term. Cochrane Database Syst Rev. 2012; (3):CD004660.

12. American College of Obstetricians and Gynecologists. Cesarean delivery on maternal request. Committee Opinion. Obstet Gynecol. 2013; 121:904-7.

13. ACOG Committee Opinion No. 578: Elective surgery and patient choice. Obstet Gynecol. 2013; 122(5):1134-8. PubMed PMID: 24150029.

14. D'Souza R, Arulkumaran S. To 'C' or not to 'C'? Caesarean delivery upon maternal request: a review of facts, figures and guidelines. J Perinat Med. 2013; 41(1):5-15. PubMed PMID: 23314510.

15. Hofberg K, Ward MR. Fear of pregnancy and childbirth. Postgrad Med J. 2003; 79(935):505-10, PubMed PMID: 13679545.

16. Rouhe H, Salmela-Aro K, Gissler M, Halmesmäki E, Saisto T. Mental health problems common in women with fear of childbirth. BJOG. 2011; 118(9):1104-11. PubMed PMID: 21489127.

17. Sydsjö G, Möller L, Lilliecreutz C, Bladh M, Andolf E, Josefsson A. Psychiatric illness in women requesting caesarean section. BJOG. 2015; 122(3):351-8. PubMed PMID: 24628766.

18. Grekin R, O'Hara MW. Prevalence and risk factors of postpartum posttraumatic stress disorder: A meta-analysis. Clin Psychol Rev. 2014; 34(5):389-401. PubMed PMID: 24952134. 


\section{Appendix}

Meta-analysis charts

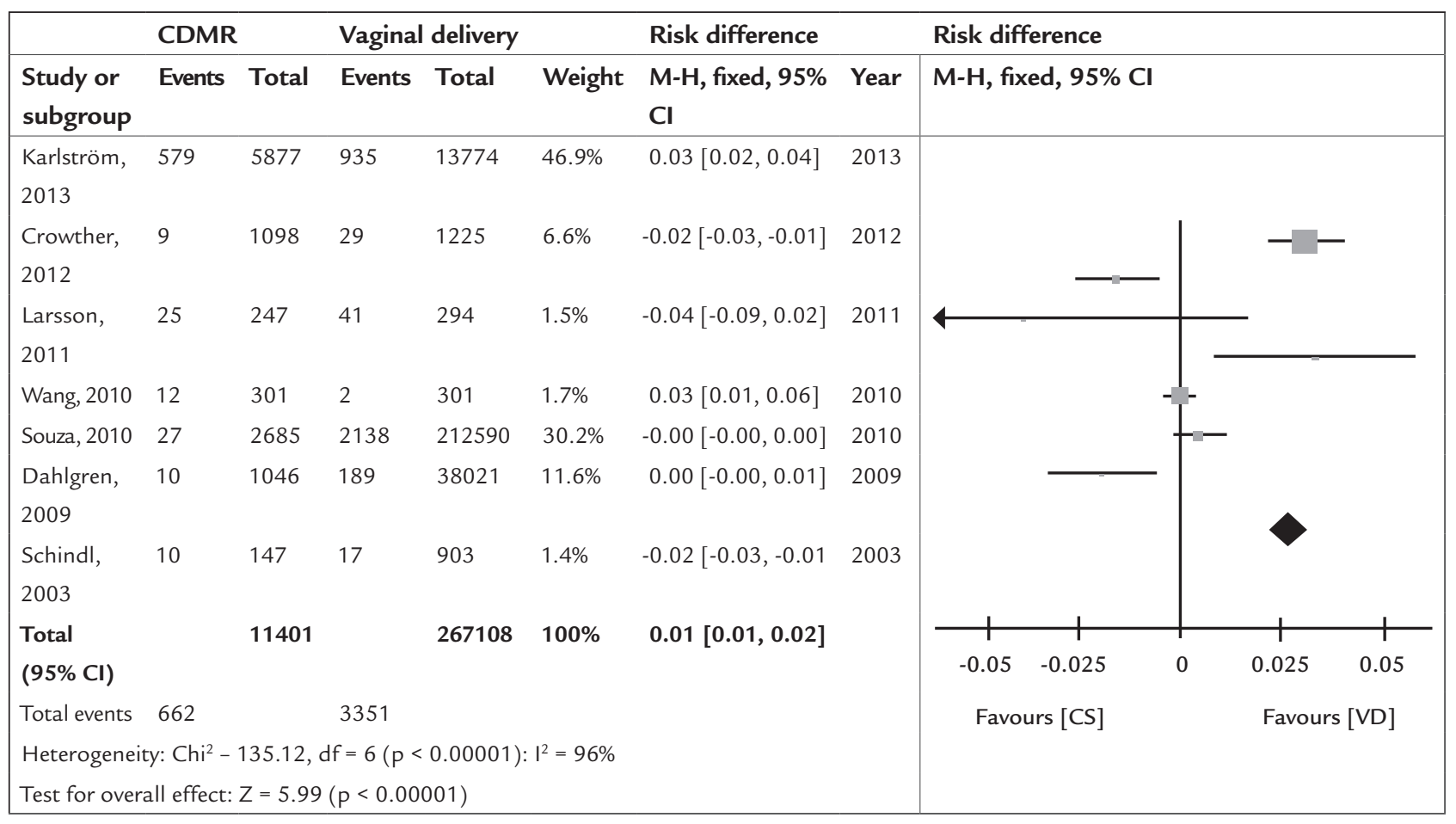

FIGURE 1.1 Bleeding complications.

\begin{tabular}{|c|c|c|c|c|c|c|c|c|c|c|c|}
\hline & CDMR & & Vaginal & deliver & & Risk differen & & Risk difference & & & \\
\hline $\begin{array}{l}\text { Study or } \\
\text { subgroup }\end{array}$ & Events & Total & Events & Total & Weight & $\begin{array}{l}\text { M-H, fixed, } \\
95 \% \mathrm{Cl}\end{array}$ & Year & M-H, fixed, $95 \% \mathrm{Cl}$ & & & \\
\hline $\begin{array}{l}\text { Karlström, } \\
2013\end{array}$ & 148 & 5877 & 155 & 13774 & $74.2 \%$ & $\begin{array}{l}0.01[0.01, \\
0.02]\end{array}$ & 2013 & & & & \\
\hline $\begin{array}{l}\text { Larsson, } \\
2011\end{array}$ & 8 & 247 & 8 & 294 & $2.4 \%$ & $\begin{array}{l}0.01[-0.02, \\
0.03]\end{array}$ & 2011 & & & & \\
\hline $\begin{array}{l}\text { Wang, } \\
2010\end{array}$ & 7 & 301 & 3 & 301 & $2.7 \%$ & $\begin{array}{l}0.01[-0.01 \\
0.03]\end{array}$ & 2010 & & & & \\
\hline $\begin{array}{l}\text { Dahlgren, } \\
2009\end{array}$ & 1 & 1046 & 104 & 38021 & $18.3 \%$ & $\begin{array}{l}-0.00[-0.00 \\
0.00]\end{array}$ & 2009 & & t. & & \\
\hline $\begin{array}{l}\text { Schindl, } \\
2003\end{array}$ & 0 & 147 & 1 & 903 & $2.3 \%$ & $\begin{array}{l}-0.00[-0.01 \\
0.01\end{array}$ & 2003 & & & & \\
\hline $\begin{array}{l}\text { Total } \\
(95 \% \mathrm{Cl})\end{array}$ & & 7618 & & 53293 & $100 \%$ & $\begin{array}{l}0.01[0.01, \\
0.01]\end{array}$ & & & & 1 & \\
\hline $\begin{array}{l}\text { Total } \\
\text { events } \\
\text { Heterogenei } \\
\text { Test for over }\end{array}$ & $\begin{array}{l}164 \\
\text { ty: } \text { Chi' }^{2}- \\
\text { all effect: }\end{array}$ & $\begin{array}{l}160.55, \\
Z=6.0\end{array}$ & $\begin{array}{c}271 \\
f=4(p< \\
(p<0.00\end{array}$ & $\begin{array}{l}0.00001 \\
001)\end{array}$ & $\mathrm{I}^{2}=98 \%$ & & & $\begin{array}{l}-0.05 \\
\quad \text { Favours [CS] }\end{array}$ & 0 & $\begin{array}{c}0.025 \\
\text { Favours [VD] }\end{array}$ & ${ }^{0.05}$ \\
\hline
\end{tabular}

FIGURE 1.2 Infectious complications. 


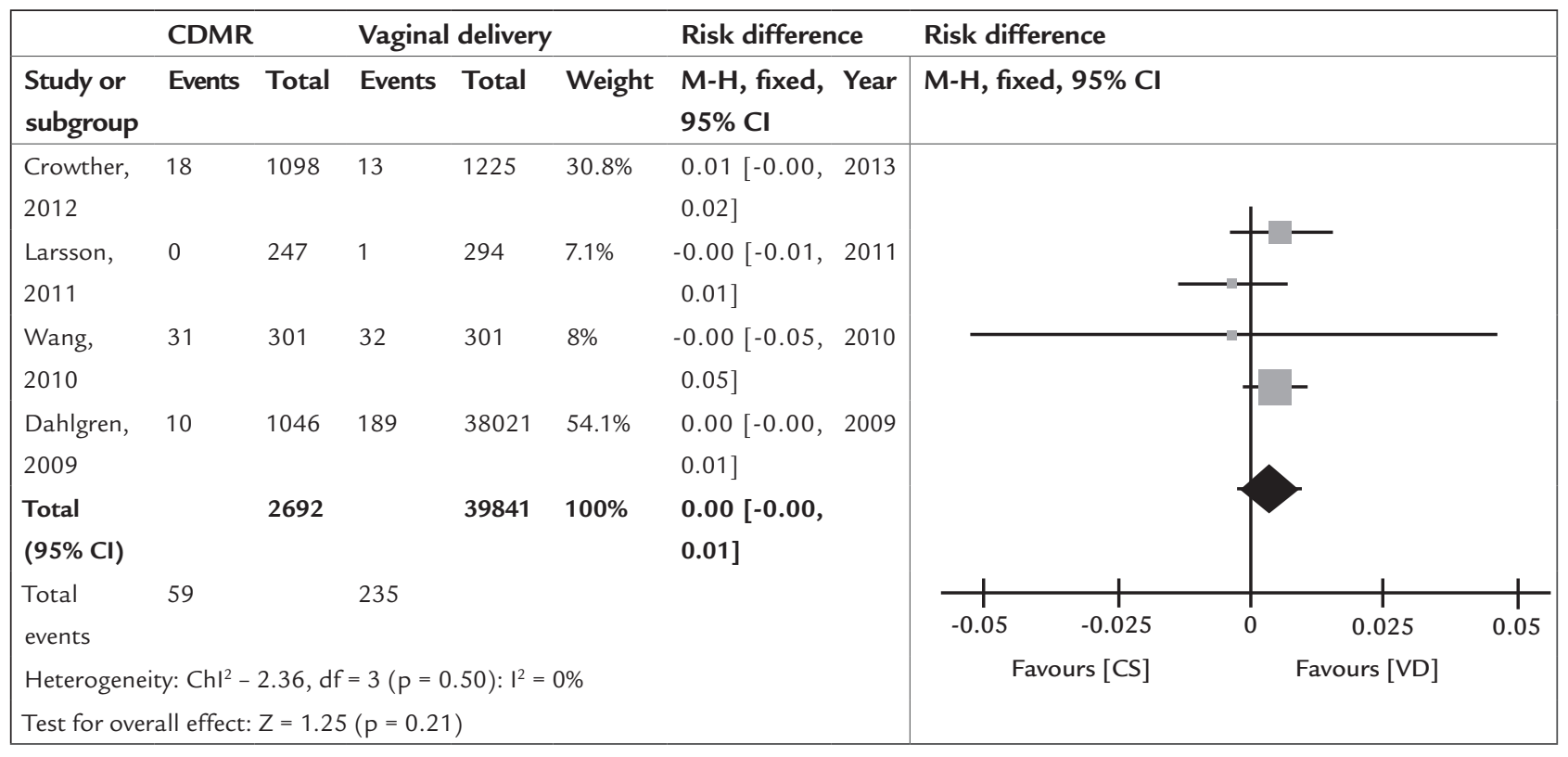

FIGURE 1.3 Wound complications.

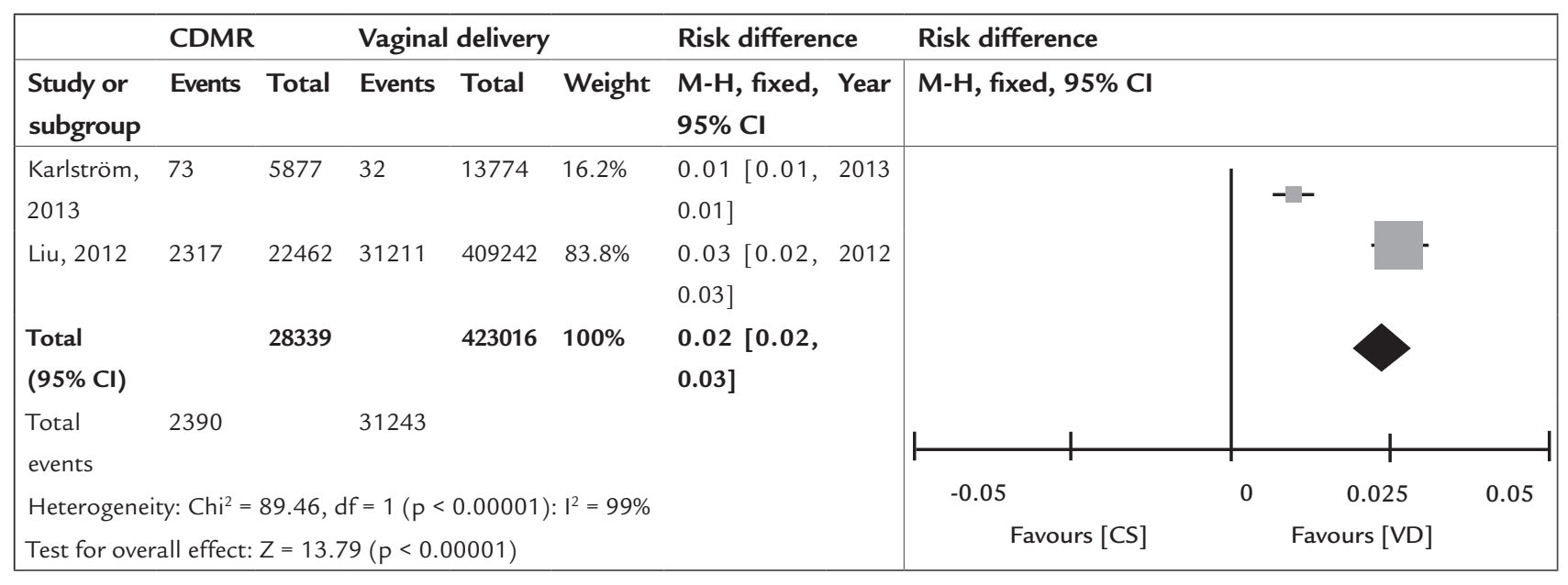

FIGURE 1.4 Breastfeeding complications. 


\begin{tabular}{|c|c|c|c|c|c|c|c|c|c|c|c|c|}
\hline \multirow[b]{2}{*}{$\begin{array}{l}\text { Study or } \\
\text { subgroup }\end{array}$} & \multicolumn{2}{|l|}{ CDMR } & \multicolumn{3}{|c|}{ Vaginal delivery } & \multicolumn{2}{|c|}{ Risk difference } & \multicolumn{5}{|c|}{ Risk difference } \\
\hline & Events & Total & Events & Total & Weight & $\begin{array}{l}\text { M-H, fixed, } \\
95 \% \mathrm{Cl}\end{array}$ & Year & M-H & xed, $95 \% \mathrm{Cl}$ & & & \\
\hline $\begin{array}{l}\text { Karlström, } \\
2013\end{array}$ & 0 & 5877 & 838 & 13774 & $68.9 \%$ & $\begin{array}{l}-0.06[-0.06 \\
-0.06]\end{array}$ & 2013 & \multirow{6}{*}{\multicolumn{2}{|c|}{ a }} & & & \\
\hline $\begin{array}{l}\text { Crowther, } \\
2012\end{array}$ & 109 & 1098 & 367 & 1225 & $9.7 \%$ & $\begin{array}{l}-0.20[-0.23 \\
-0.17]\end{array}$ & 2012 & & & & & \\
\hline $\begin{array}{l}\text { Larsson, } \\
2011\end{array}$ & 25 & 247 & 45 & 294 & $2.2 \%$ & $\begin{array}{l}-0.05[-0.11 \\
0.00]\end{array}$ & 2011 & & & & & \\
\hline $\begin{array}{l}\text { Dahlgren, } \\
2009\end{array}$ & 0 & 1046 & 5580 & 38021 & $17 \%$ & $\begin{array}{l}-0.15[-0.15 \\
-0.14]\end{array}$ & 2009 & & & & & \\
\hline $\begin{array}{l}\text { Schindl, } \\
2003\end{array}$ & 0 & 147 & 93 & 903 & $2.1 \%$ & $\begin{array}{l}-0.10[-0.12 \\
-0.08]\end{array}$ & 2003 & & & & & \\
\hline $\begin{array}{l}\text { Total } \\
(95 \% \mathrm{Cl})\end{array}$ & & 8415 & & 54217 & $100 \%$ & $\begin{array}{l}-0.09[-0.09 \\
-0.09]\end{array}$ & & & & & & \\
\hline $\begin{array}{l}\text { Total } \\
\text { events } \\
\text { Heterogenei } \\
\text { Test for over }\end{array}$ & $\begin{array}{l}134 \\
\text { ity: } \mathrm{Chi}^{2}- \\
\text { call effect }\end{array}$ & $\begin{array}{l}1120.43 \\
Z=40\end{array}$ & $\begin{array}{c}6923 \\
, d f=4(p \\
1(p<0.0\end{array}$ & $\begin{array}{l}<0.000 \\
0001)\end{array}$ & 1): $I^{2}=10$ & & & \multicolumn{2}{|r|}{ Favours [CS] } & 0 & $\begin{array}{r}0.1 \\
F\end{array}$ & $\begin{array}{c}0.2 \\
\mathrm{VD}]\end{array}$ \\
\hline
\end{tabular}

FIGURE 2 Emergency C-section.

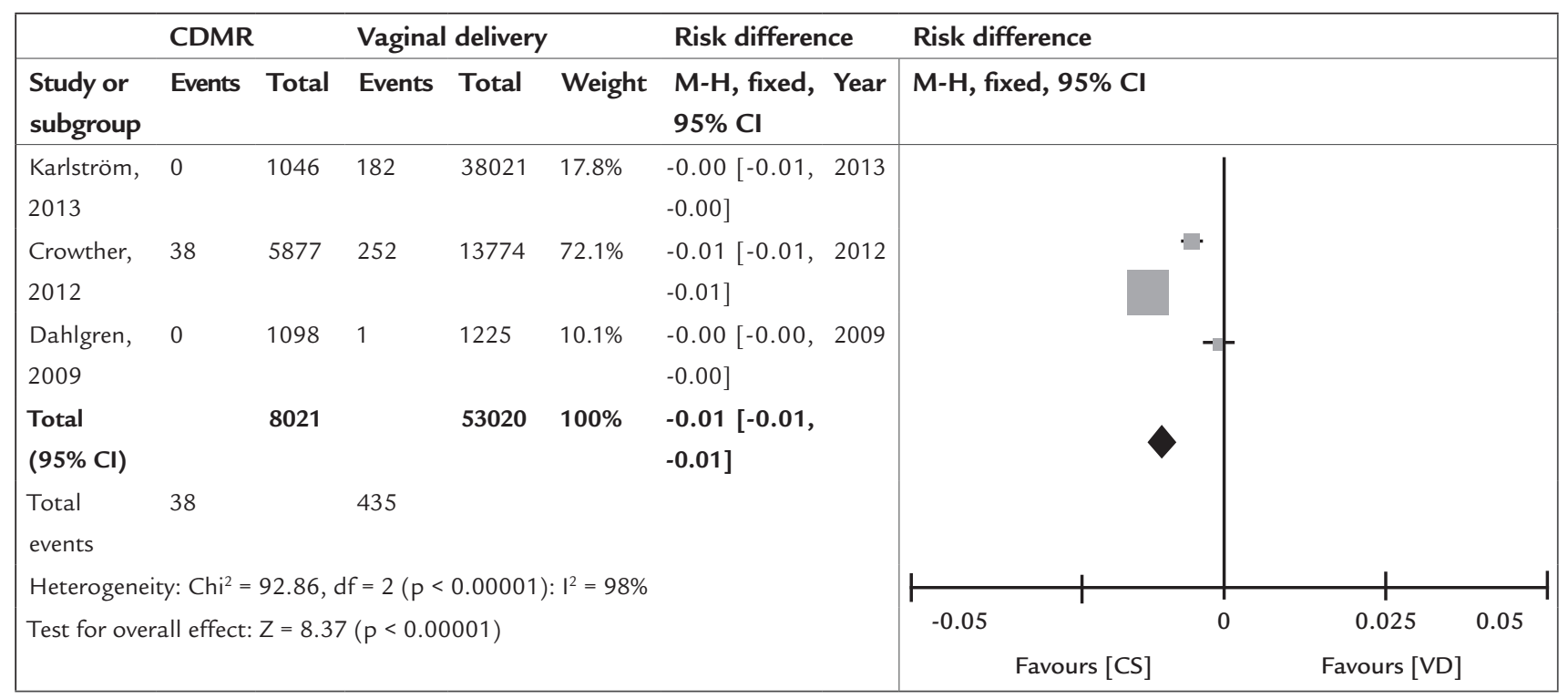

FIGURE 3.1 Decrease in Apgar score. 


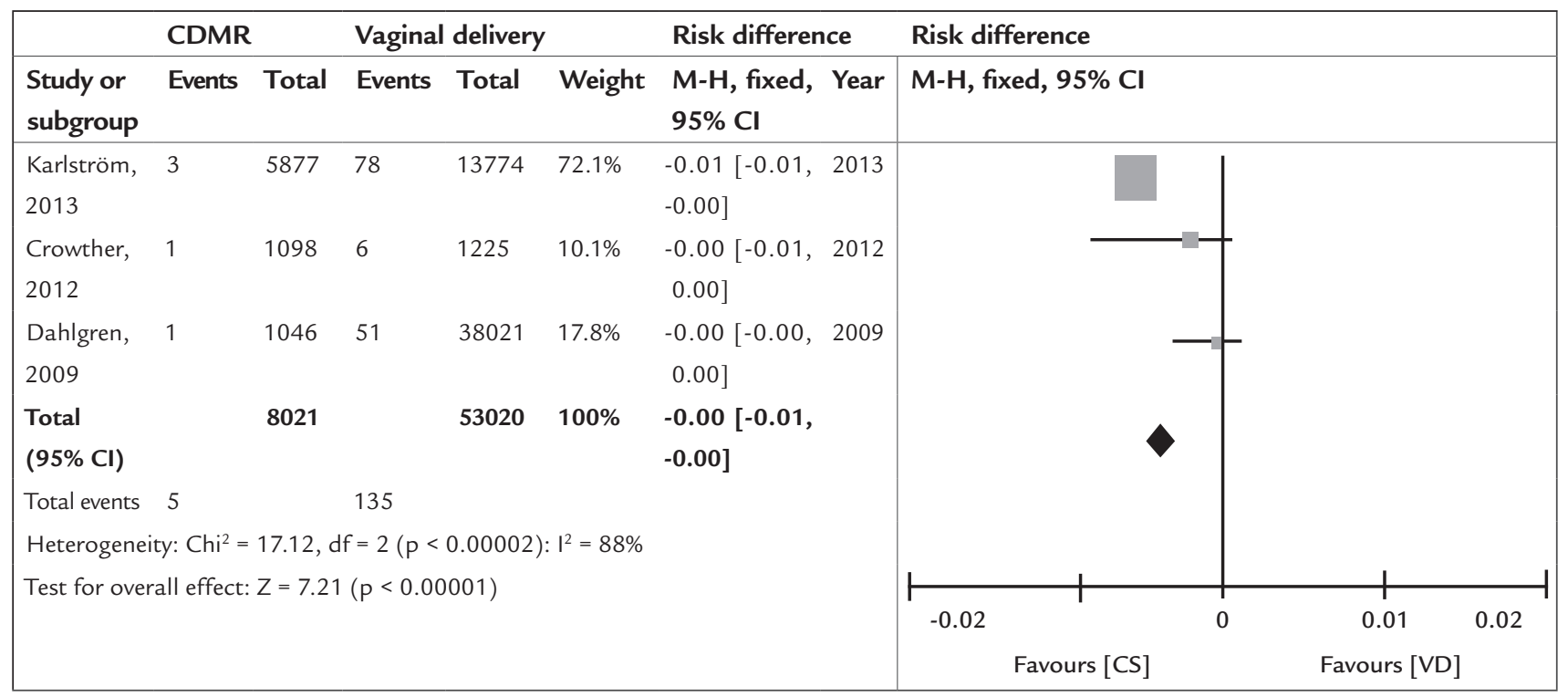

FIGURE 3.2 Neonatal asphyxia.

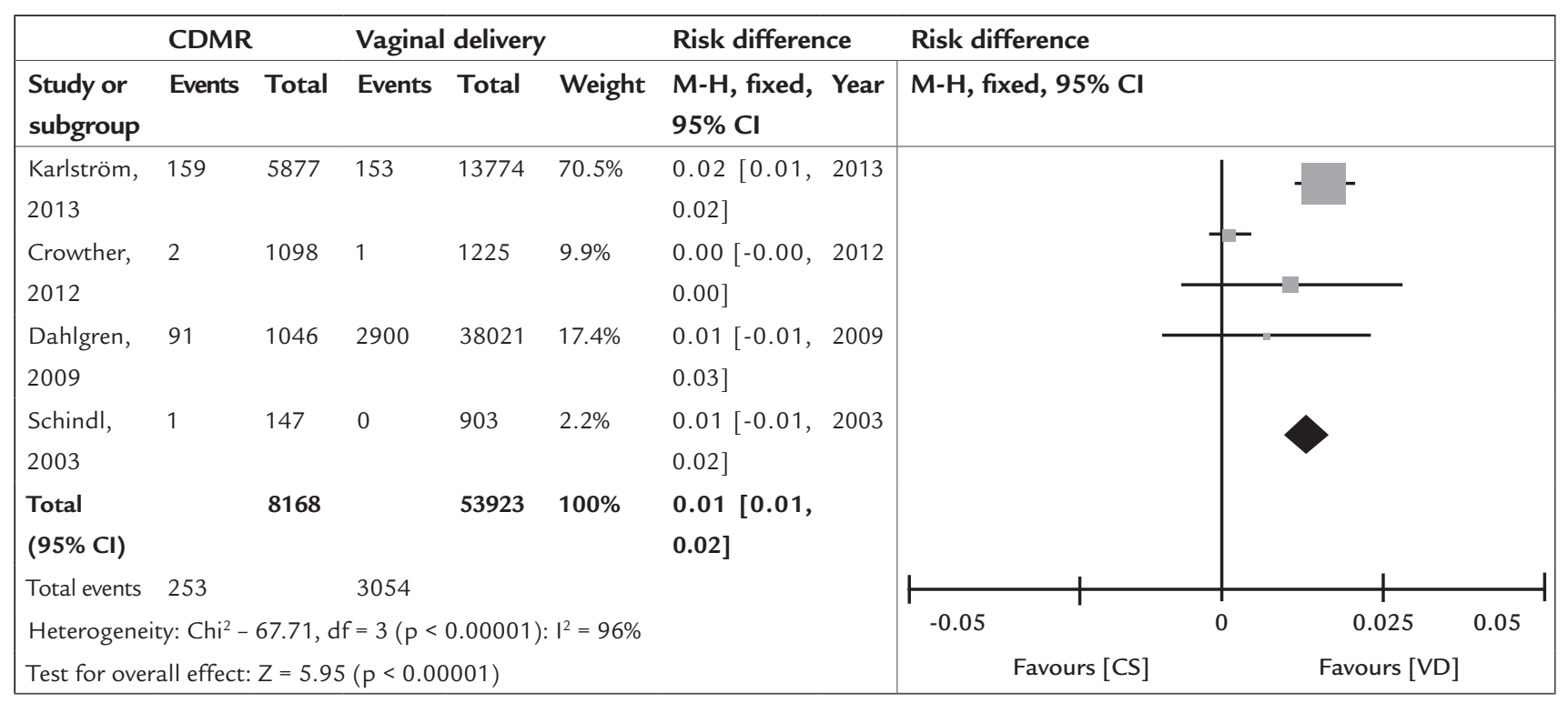

FIGURE 3.3 Respiratory complications. 


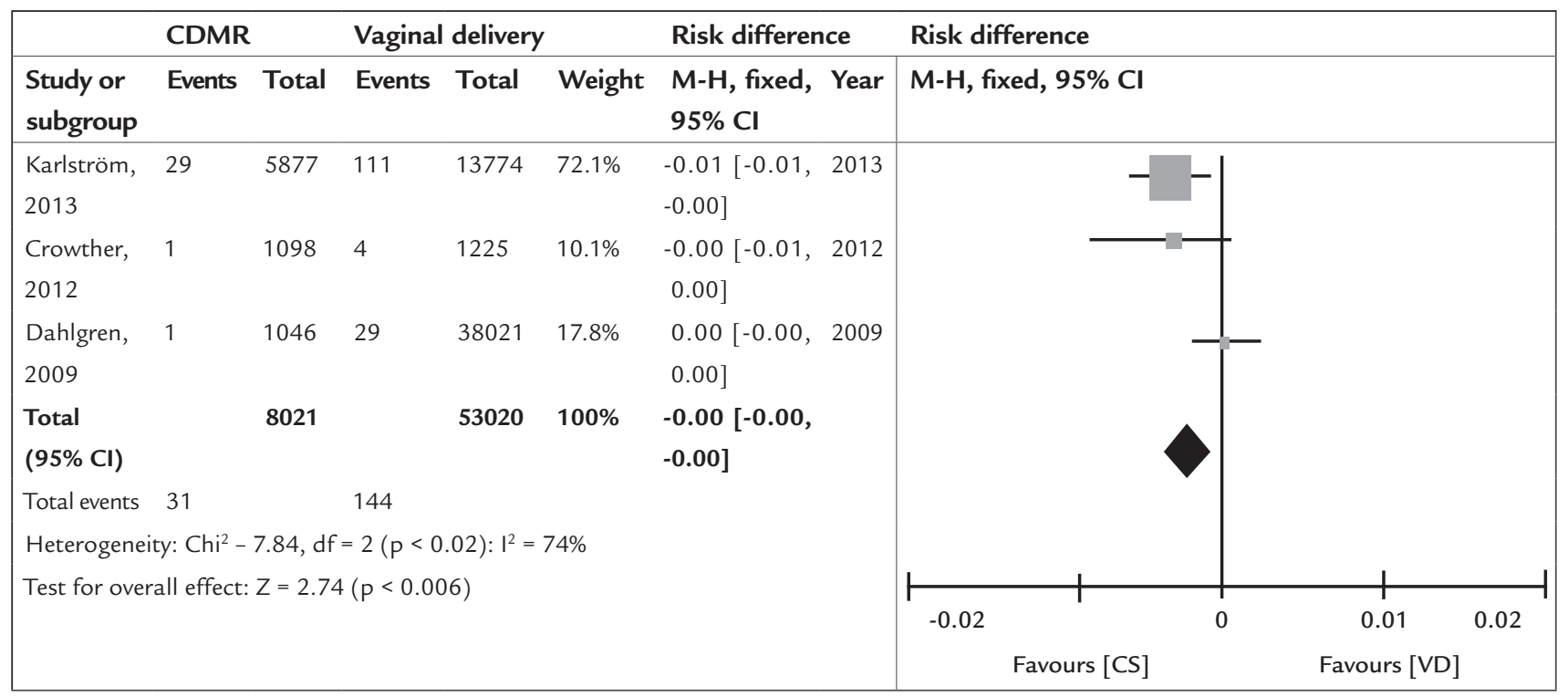

FIGURE 3.4 Newborn infection.

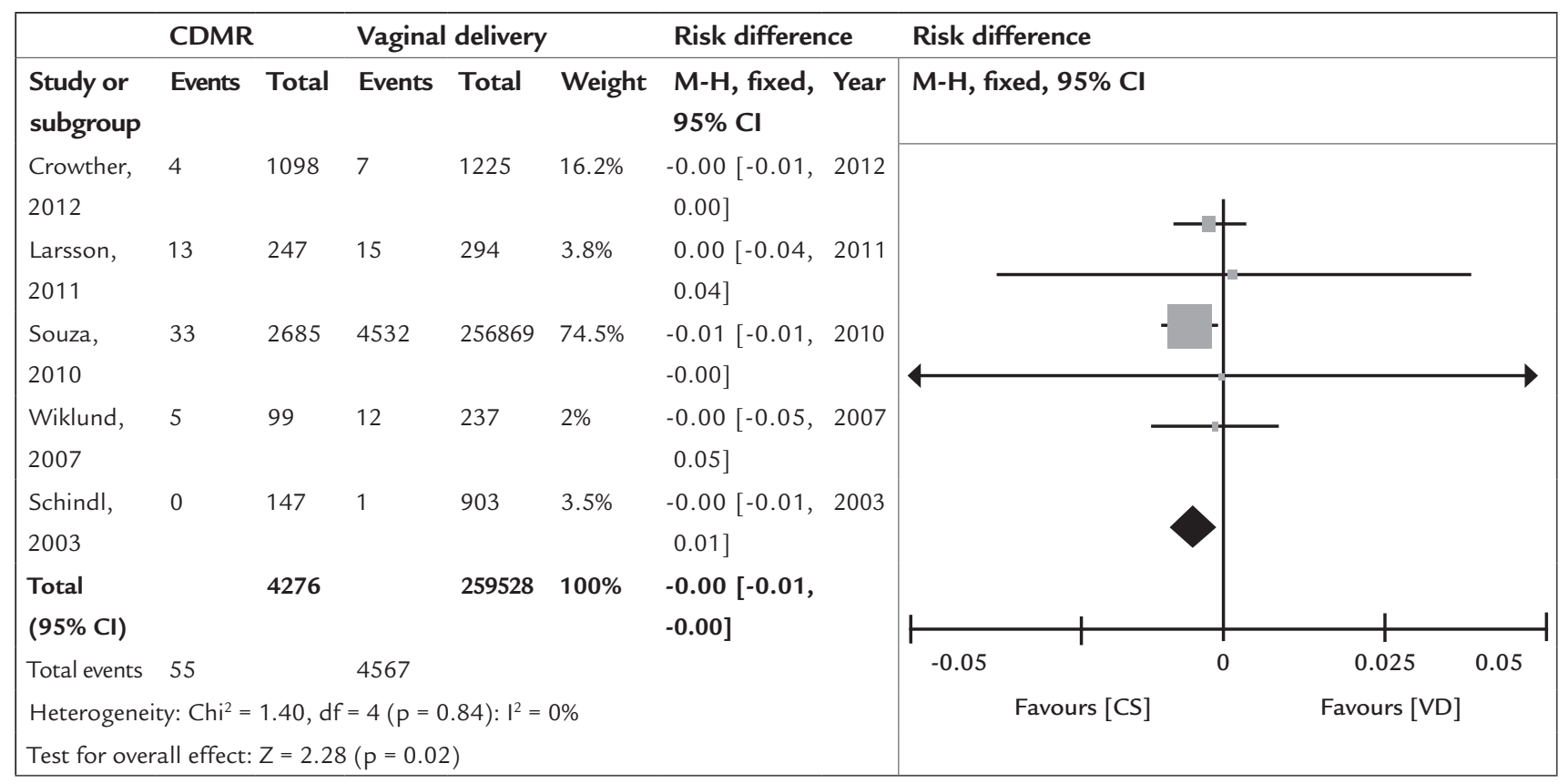

FIGURE 3.5 Admission to neonatal ICU. 